\title{
LINDOLFO COLLOR E SUA PROPOSTA DE CONCILIAÇÃO ENTRE CAPITAL E TRABALHO
}

\section{LINDOLFO COLLOR AND HIST PROPOSITION OF THE CONCILIATION BETWEEN CAPITAL AND LABOR}

\author{
Pedro Paulo Lima Barbosa'
}

\section{RESUMO}

Em nosso artigo procuraremos apontar como Lindolfo Collor pensou a conciliação entre capital e trabalho ao longo de sua atuação política. As justificativas para estudarmos suas ações justificam-se a partir do momento em que ele esteve à frente de importantes movimentos de sua época bem como de ter sido o primeiro Ministro do Ministério do Trabalho, Indústria e Comércio. De certa forma, Collor foi a pessoa responsável por dar a tônica dos encaminhamentos que as leis sociais e trabalhistas implantadas no país. Em suas ações político-sociais, ele buscou dirimir os embates entre capital e trabalho via ação do Estado e com soluções que estivessem de acordo com o desenvolvimento e as necessidades do Brasil.

Palavras-chave: Lindolfo Collor - Conciliação entre classes - Capital Trabalho.

\begin{abstract}
In our issue we will try to point out how Lindolfo Collor thought the conciliation between capital and labor throughout his political activities. The justifications for studying their actions are justified from the moment he was at the forefront of important movements of his time as well as being the first Minister of the Ministry of Labor, Industry and Commerce. In a way, Collor was the person responsible for giving the keynote of referrals to social and labor laws implemented in the country. In their actions-political, he sought to resolve the conflicts between capital and labor through state action and solutions that were consistent with the development and the needs of Brazil
\end{abstract}

Keywords: Lindolfo Collor - Classes - Conciliation - Capital - Labor.

\section{INTRODUÇÃO}

Os estudos sobre o movimento operário, bem como as questões ligadas a ele são políticos. Assim, a produção historiográfica sobre 0 operariado, na maioria das vezes, refletem posições, comportamentos, 
ideologias de uma época que, no geral, são mais voltadas à 'esquerda', pois como lembrou-nos o historiador Eric Hobsbawm o posicionamento de nós historiadores frente a classe operária situa-se "num ponto de encontro entre os estudos acadêmicos e a política, entre compromissos de ordem prática e compreensão teórica, entre interpretar o mundo e transformá-lo." ${ }^{2}$

O engajamento político dos estudiosos é visto pelo referido autor como "na maioria [e] ao mesmo tempo acadêmicos e de esquerda." Em consequência disso, a literatura produzida por esses mesmos estudiosos, que versa sobre o movimento e temas correlacionados, muitas vezes, tratam não como o movimento foi de fato, mas sim como gostaria que tivesse sido. ${ }^{4}$

Não é de hoje que se discute o 'ovo de Colombo', isto é, se a questão social e trabalhista foi resultado de conquista, dádiva/outorga ou, ainda, de uma antecipação das reivindicações operárias. Nosso objetivo, aqui nesse trabalho, é trazer à baila alguns elementos das ações de pessoas como Lindolfo Leopoldo Boeckel Collor que contribuíram de forma significativa para mudar o rumo que essas questões estavam tomando.

Em suas ações, enquanto político que esteve à frente do Ministério do Trabalho, Indústria e Comércio, Lindolfo Collor procurou atenuar os conflitos entre capital e trabalho buscando a conciliação entre ambos os grupos sociais, a saber: burguesia e proletariado via atuação do Estado.

Assim, ao buscar a conciliação entre capital e trabalho, o Ministério do Trabalho tornou-se mais um espaço em que se deu o enfrentamento entre burgueses e trabalhadores, um lócus privilegiado em que ambos os grupos deixam suas marcas, suas reivindicações, enfim, sua história de vida e luta entre classes.

\section{AS TENDÊNCIAS DO MOVIMENTO OPERÁRIO E A QUESTÃO SOCIAL E TRABALHISTA}

Podemos destacar três grandes correntes que, em grau diverso, tiveram influência no movimento operário e que, por sua vez, movimentaram o aparato do Estado e diversos segmentos da sociedade, principalmente das 
elites políticas, em respostas às suas ações, eram elas: o socialismo reformista, o anarquismo e o trabalhismo. ${ }^{5}$

Embora possa parecer anacrônica a afirmação da existência de marxistas já na virada do século XIX para o XX, acreditamos, assim como Cláudio Henrique de Moraes Batalha ${ }^{6}$ que:

\begin{abstract}
Essa afirmação é correta se pensarmos o marxismo como limitado ao pensamento de Marx (...) os socialistas brasileiros que atuaram na última década do século XIX e nos primeiros anos deste século [do século $\mathrm{XX}$ ], podem não ser marxistas pelos critérios de hoje, mas seriam classificados como tais pelos critérios de seu tempo.
\end{abstract}

Assim, a corrente socialista no Brasil, como nos demonstra Batalha, surgiu ainda no final do século XIX no país. Contudo, é somente após a Revolução Bolchevique de 1917, na Rússia que ela ganhou maior visibilidade. Porém, segundo Boris Fausto, ${ }^{7}$ os sinais socialistas em São Paulo, no início do século XX, por exemplo, eram maiores do que os dos anarquistas.

Tal proposta, no entanto, até o final da década de 1910, obteve pouca ressonância na sociedade devido suas características rurais, sua forma precária desenvolvidas industrialmente o que gerava um baixo número de operariado urbano e certo grau de legitimação dos grupos dominantes da época. ${ }^{8}$

A influência anarquista no movimento operário data de 1906, concomitante ao I Congresso Operário ocorrido no Rio de Janeiro. A partir daí, até os anos que se seguiram à Primeira Guerra Mundial (1914-1918), foram os anarquistas os maiores responsáveis pela caracterização das ações e dos setores organizados do movimento operário no Brasil. $^{9}$

Os anarquistas ciosos de adentrar o solo fértil do movimento operário, na busca da criação de uma identidade da classe trabalhadora e ao mesmo tempo em que defendesse uma autoimagem do trabalhador como também um engajamento em sua luta com dimensões e objetivos políticos específicos do movimento anarquista no país, buscaram construir uma identidade do movimento operário e, ao mesmo tempo, certo engajamento em sua luta política. ${ }^{10}$ 
Ora, ao longo de todo o período da Primeira República e a Era Vargas ocorreram grandes transformações e agitações sociais, haja vista as greves que, praticamente, se sucederam durante todo esse período, o que levou à promulgação de várias leis sociais, como por exemplo, a criação do Departamento Nacional do Trabalho, criado em $1918 .^{11}$

Por seu turno, a terceira corrente ${ }^{12}$ que influenciou os trabalhadores da época foi o trabalhismo que, embora em menor proporção, não pode ser considerada pequena no que tange a sua influência no movimento operário. Segundo Boris Fausto, essa corrente apresentou dois fenômenos significativos ao longo da Primeira República: parte do movimento operário em se submeter a 'batuta' do Estado, bem como a presença de setores sociais dispostos a buscar uma conciliação com o movimento operário. ${ }^{13}$

Nessa perspectiva, haveria, então, por parte do Estado e da classe trabalhadora, um acordo tácito, ou seja, por meio de um projeto articulado por parte do Estado, a classe trabalhadora foi incorporada ao mundo do trabalho, incidindo na conquista dos direitos sociais adquiridos por lei a seu grupo de trabalhadores, daí o 'trabalhismo' brasileiro. Desse modo, para que possamos entender o trabalhismo colocado em prática na Era Vargas, pensamos ser importante estudarmos a figura de Lindolfo Collor.

Para ele, a interpretação social originária a partir do liberalismo teve como consequência o surgimento do socialismo e comunismo. Estes surgiram, apenas devido a equívocos daquele, ou seja, como uma resposta; engendrando mediante o momento em que se pensou o liberalismo como solução aos problemas sociais tornando uma querela entre o materialismo histórico e o liberalismo clássico:

O liberalismo clássico, que procurou sistematizar as relações de causa e efeito entre os fenômenos econômicos, fez da economia a ciência do capitalismo. Esse erro engendrou, em forma de resposta, outro erro: o do materialismo histórico. Eis aqui uma verdade de aparência paradoxal, mas para meu uso particular perfeitamente assentada: Ricardo e os fisiocratas, Adam Smith e os doutrinários de Manchester, Bastiat e os partidários do laissez faire foram precursores necessários de Karl Marx e do comunismo. Economia liberal igual a capitalismo; materialismo histórico igual a comunismo: aqui temos a tese e a antítese que formam a síntese da anarquia do século $X X^{14}$ 
Para Collor, o erro causado mediante interpretação do liberalismo clássico de que o Estado não deveria imiscuir-se nas questões econômicas e sociais freou, por outro lado, a reação do materialismo histórico em atacar o liberalismo e o Estado democrático. Na época a qual Collor escreveu o excerto supracitado estava em pauta a busca por revisão de valores. Dentre esses valores, estava a concepção de Estado que se buscava. Um estado de direito moderno, democrático o qual era abalado pela preponderância do econômico sobre o político. Esta, por sua vez, seria senão a principal, uma das mais importantes medidas na busca de novos valores no campo econômico, político e social.

Os fenômenos sociais, mais do que outros quaisquer, hão de ser tratados não apenas com a modéstia decorrente da nossa pobreza de conhecimentos, mas aproximados com a humildade de quem Ihes queira surpreender possíveis relações de causa e efeito, jamais com jactância de quem pretende impor-lhes leis forjadas ao sabor das suas próprias ilusões ou conveniências. ${ }^{15}$

$\mathrm{Na}$ elaboração do programa da Aliança Liberal, Lindolfo Collor, segundo um de seus contemporâneos que o auxiliou no Ministério do Trabalho, Heitor Muniz, fez o seguinte comentário em entrevista cedida ao Centro de Pesquisa e Documentação de História Contemporânea do Brasil (CPDOC), da Fundação Getúlio Vargas no Rio de Janeiro: "Quando da formação da Aliança Liberal, o Collor foi uma das pessoas que ajudaram o Getúlio Vargas na elaboração da plataforma da Aliança. Nessa plataforma da Aliança Liberal já se encontram todos os fundamentos do que seria a nova política social a ser implantada no Brasil."16

Havia um projeto de desenvolvimento social planejado por Lindolfo Collor. Evidentemente, esse projeto era parte integrante das elites políticas da época. Cada classe ou segmento de classe atua em defesa de seus interesses junto ao Estado. Mas, ainda que grupos e segmentos sociais tenham expressado seus interesses na arena política, o fato é que o fizeram por meio de atores. Por isso, se de um lado não se pode esquecer a atuação política e social dos indivíduos, não se pode igualmente deixar de considerar a ação dos agentes sociais que tomaram como tarefa expressar esses interesses. 
Enquanto um dos líderes da segunda geração dos castilhistas, Lindolfo Collor tinha como um de seus principais ideais políticos a ideia de criar a justiça social no Brasil. ${ }^{17}$ Já em 1917, em artigo publicado no jornal $A$ Tribuna, na cidade do Rio de Janeiro, demonstrara uma clara visão sobre o problema da questão social no Brasil e no mundo:

\begin{abstract}
Engana-se profundamente quem supuser que dentro da nova ordem de coisas que nasce com o fim da luta das potências, será possível ainda ir iludindo a verdadeira situação do proletariado e adiando a sua definitiva incorporação moral e econômica na civilização ocidental, que é também a nossa. A consciência do mundo está amadurecendo para a reforma social. Um ano, dois, cinco, dez, o prazo final pouco importa. O fato é que os explorados se levantam contra os exploradores. Uma mentalidade retrógrada poderia objetivar que isto é uma coisa velha, que Spartacus já tentou em Roma o que a Revolução Francesa impôs, em parte, ao mundo. Mas a verdade das coisas é muito diferente. $O$ que não passa de arrancos pessoais ou, quando muito de movimentos nacionais é hoje uma aspiração universal. A balança social se mantinha em equilíbrio até aqui, porque num dos seus pratos pesava o ferro das carabinas, o aço das espadas, o bronze dos canhões. Mas basta que o espírito da época se levante contra a continuação da paz armada - e isto que está sucedendo em face do tratado que a "Entente" impõe aos vencidos para que o equilíbrio se rompa definitivamente. E já então será possível dizer com exatidão a que espetáculos assistirá o mundo atônito e até onde irá a resistência da nossa civilização, cujas conquistas estão sendo malbaratadas por espíritos que não compreendem as grandes verdades que andam no ar. ${ }^{18}$
\end{abstract}

Esta incorporação à sociedade de direito para ele deveria se dar por conta das mudanças inevitáveis às quais o mundo passava. Collor mostrou como deveriam ser tratados os movimentos sociais, que ganhavam força no Brasil e no mundo. Para ele, fazia-se necessário trazer à baila a questão social, a fim de se resolverem os embates entre capital e trabalho, pois não mais seria possível ignorar a existência do problema social.

Nesse mesmo artigo, Lindolfo Collor apresentou um dos princípios defendidos por ele e sua equipe enquanto esteve à frente do Ministério do Trabalho, Indústria e Comércio: uma legislação social que estivesse de acordo com o desenvolvimento do país e que fosse obra genuinamente nacional.

Como as condições econômicas variam infinitamente de Estado a Estado, compreende-se que neste particular - e eu tenho como fora de dúvida que este é o aspecto central da questão - nós temos que fazer obra nossa, exclusivamente nossa, procurando ver, antes de tudo, onde estão, para o bem-estar do proletariado, as falhas do 
nosso sistema econômico, a fim de lhe dar remédio seguro e de acordo com as possibilidades e imposições do meio. ${ }^{19}$

Cabe observar que, além de defender uma legislação social que fosse "exclusivamente nossa", e não uma cópia de legislações de outros países as leis deveriam estar em consonância com o grau de desenvolvimento do país. Em seus discursos, ele associava as questões econômicas às questões sociais. Por conseguinte, tais questões seriam inerentes ao processo de desenvolvimento do capitalismo, representando "um fenômeno mundial, [...] demonstração de vida, de progresso".

Em artigo publicado no jornal Correio do Povo, Lindolfo Collor apresentava uma solução aos problemas econômicos advindos da Grande Depressão de 1929 estava relacionada às questões sociais:

Não tenho dúvida e, repetir-Ihe o que tenho dito, tantas vezes em discursos e documentos políticos, desde 1929: a única política em consonância com os imperativos do nosso tempo é a política social. Os fenômenos coletivos, contemporaneamente, só admitem soluções sociais. Cada ciclo histórico tem a sua característica própria. O século XVIII foi o século político: a Enciclopédia, a Revolução Francesa, os Direitos do Homem; o século XIX foi o século econômico: a base do individualismo, conquista da Revolução Francesa, operou a humanidade, nos tempos modernos, o seu maior progresso de civilização material. Mas essa civilização material, verdadeira revolução industrial - o vapor e as suas aplicações ao comércio dos transportes, a eletricidade, etc. - em nada modificou, substancialmente, a situação do proletariado, da grande massa. A civilização industrial foi uma regalia de elites. Assim, esperando por novas soluções, começou o século $X X$, que será o século social. Não nos iludamos a este propósito, porque a ilusão só permitida aos surdos de consciência e aos cegos de compreensão. Na parábola da evolução humana, o século terá a missão de aplicar socialmente as conquistas políticas do século XVIII e os progressos econômicos do século XIX. Nós vivemos em uma época de nivelação. As desigualdades sociais estão feridas de morte e já cambaleiam nos estertores de um regime econômico que, de tanto se preocupar com os fenômenos materiais da produção e da circulação, acabou asfixiado sob as riquezas que acumulou e às quais não soube dar aplicação social. ${ }^{20}$

A Lindolfo Collor a sociedade passava por mudanças políticas, econômicas e sociais. Tais mudanças, no entender do autor, somadas à industrialização, causariam desemprego em grande quantidade e subtração de uma massa de consumidores, o operariado. 


\section{A CONCILIAÇÃO ENTRE CAPITAL E TRABALHO EM LINDOLFO COLLOR}

Divisor de águas, a Revolução de 1930 é considerada por muitos estudiosos o início de uma nova Era no processo legislativo trabalhista. Para alguns, inexistia a legislação social e trabalhista na Primeira República; para outros, porém, o mérito do novo governo implantado com a Revolução foi ter sistematizado um direito já existente.

Contemporâneo de Lindolfo Collor e da Revolução, um dos precursores no debate sobre a legislação trabalhista e, de certa maneira, inspirador de outros estudiosos do assunto foi Dário de Bittencourt, ${ }^{21} \mathrm{em}$ seu livro sobre a história da legislação trabalhista, considera que tal legislação foi anterior a 1930: "Não foi tão insignificante assim, é bem de ver, o labor de nossos legisladores, no âmbito trabalhista, anteriormente a 1930; o que então, se verifica, era uma reacionária má vontade, no tocante ao cumprimento."22

De fato, já na Primeira República havia um arcabouço da legislação trabalhista; o problema, no entanto, residia na especificidade da legislação, pois era entendida e tratada não como uma questão política, mas como um problema moral e sanitário. Quem trouxe a legislação para o debate político foi, sem sombra de dúvida, Lindolfo Collor, que, em seu manifesto da Aliança Liberal, como bem lembrou Ângela Maria de Castro Gomes, ${ }^{23}$ afirmava: "É sobre esse aspecto [o de dar à questão social um tratamento político] que a Aliança Liberal inova, pois assume a questão social como uma questão política da modernidade, esvaziando-a de todo conteúdo negativo que até então a caracterizava."

\footnotetext{
Existe a questão social porque não poderia deixar de existir: existe nas cidades, nas vilas, nos campos; no comércio, nas indústrias urbanas, na lavoura, nas indústrias extrativas; existe por força da imigração, que fugirá aos nossos portos, se não protegermos convenientemente os trabalhadores alienígenas. A existência da questão social entre nós nada tem de grave ou de inquietador: ela representa um fenômeno mundial, é demonstração de vida, de progresso. O que de inquietador e grave aparece no Brasil é a preocupação pública de ignorar oficialmente a existência de problemas dessa natureza e desse alcance. ${ }^{24}$
}

Criado em 26 de novembro de 1930, por meio do Decreto Federal oㅡ 19.433, o Ministério do Trabalho, Indústria e Comércio, como reza o seu Art. 2ํㅡ, 
tinha "a seu cargo o estudo e despacho de todos os assuntos relativos ao trabalho, indústria e comércio." 25

Esse ministério criado por Getúlio Vargas, como salienta o historiador Orlando Barros, foi o da "questão social". ${ }^{26}$

No momento da criação do novo ministério, quando se realizava a diagnose dos problemas a enfrentar, uma questão importante se apresentou: o novo organismo teria por missão cuidar não só do trabalho, como também da indústria e do comércio. De um ponto de vista lógico, tratava-se do ministério da "questão social", isto é, sua abrangência compreendia interesses opostos, que deveria conciliar, com forte propensão a destinar-se à ambiência urbana ${ }^{27}$

Ao assumir o posto como Ministro do Trabalho, sua principal tarefa era encontrar soluções às necessidades específicas do Brasil. Porém isso não fez com que ele se voltasse aos problemas enfrentados em outros países, os quais poderiam servir de lição para o Brasil em seu processo de elaboração da legislação social. Não seria possível espelhar-se em outros países, por melhor que fossem suas leis e por mais que beneficiasse o operariado ou até mesmo o patronato elas não serviriam à realidade brasileira.

As experiências e observações em outros povos serão por nós cuidadosamente consultadas e tomadas em considerações. Mas os problemas brasileiros decorrentes de causas especificamente nossas e traduzindo situações peculiares ao nosso grau de desenvolvimento, esses não podem ser resolvidos com mentalidade estrangeira, impossível de transplantar liberal para o nosso meio. Os princípios são universais, a sua aplicação, nacional. ${ }^{28}$

Poucos dias após assumir o recém-criado Ministério do Trabalho, em discurso realizado no Rotary Club, na cidade do Rio de Janeiro, em 26 de dezembro de 1930, Collor falou da importância da união entre as classes sociais para a resolução dos seus problemas, a qual se tornou objeto central da Pasta do Trabalho.

Por isso mesmo, que todo esforço brasileiro deve tender para a grandeza e felicidade do Brasil, nem os operários nem os patrões têm o direito, por mais justo que sejam os seus interesses $e$ reivindicações de perder de vista a própria sorte do país, que é que está em jogo e deve preocupar as atenções de todos nós. Toda a agitação deve ser denunciada como inútil e impatriótica neste momento, quando o governo se esforça por garantir o regular exercício do trabalho dentro das nossas fronteias. É tempo já de substituirmos o velho e negativo conceito de luta de classes pelo 
conceito novo, construtor e orgânico de colaboração de classes. A nova República Brasileira propõe-se a dar expressão legal e real a essas novas diretrizes sociais. A luta das classes encontra as suas origens em condições retrógradas, que nós refugamos por absurdas e atentatórias da própria dignidade do Estado. Tanto o capital como o trabalho merecem e terão o amparo e proteção do Governo. As forças reacionárias do capital e as tendências subversivas do operariado são igualmente nocivas à Pátria e não podem contar com o beneplácito dos poderes públicos. Capital e trabalho no Brasil têm uma função brasileira a cumprir, e essa função se há de realizar dentro dos mais rigorosos ditames da justiça ${ }^{29}$

Para Lindolfo Collor, o Estado deveria se fazer presente e assegurar as mínimas condições para o desenvolvimento capitalista no Brasil. À questão social no país não cabia mais medidas reacionárias e ineficientes frente aos embates entre capital e trabalho, ao contrário, o "velho e negativo conceito de lutas" deveria dar espaço a outra solução: "uma colaboração entre as classes". Para que se chegasse a essa colaboração, as organizações sindicais tanto do operariado quanto do patronato adquiririam destaque na nova organização social.

Durante o período que esteve à frente do Ministério, teve forte oposição tanto da burguesia quanto do proletariado. Estes o acusavam de favorecer as classes dominantes, aqueles, por sua vez, consideravam-no como defensor dos interesses dos trabalhadores em detrimento do capital.

Ora, nem uma coisa, nem outra. A centralização e controle por parte do Poder Executivo, trazendo para si o papel de mediar as questões sociais e trabalhistas no país, o 'Ministério da Revolução, tornou-se um novo espaço de enfrentamento das questões trabalhistas. A Lei, apesar de ser sopesada como instituição criada pelas classes dominantes, não pode ser encarada como via de mão única, como benefício único destinado apenas àqueles que a criou. Ao contrário, ao se estabelecer as leis, as classes dirigentes também são submetidas a elas, tornando-se, tal como as classes subalternas, submissas a sua própria retórica.

Edward Palmer Thompson, em Senhores e Caçadores, coloca que a Lei tem suas características próprias, bem como sua lógica, sua história. Para Thompson, 
A maioria dos homens tem um forte senso de justiça, pelo menos em relação aos seus próprios interesses. Se a lei é manifestadamente parcial e injusta, não vai mascarar nada, legitimar nada, contribuir em nada para a hegemonia de classe alguma. A condição prévia essencial para a eficácia da lei, em sua função ideológica, é a de que mostre uma independência frente a manipulações flagrantes e pareça ser justa. Não conseguirá parecê-lo sem preservar sua lógica e critérios próprios de igualdade; na verdade, às vezes sendo realmente justa. $E$, ademais, não é frequentemente que se pode descartar uma ideologia dominante como mera hipocrisia; mesmo os dominantes têm necessidade de legitimar seu poder, moralizar suas funções, sentir úteis e justos. ${ }^{30}$

Analisando as leis criadas por Lindolfo Collor enquanto esteve à frente do Ministério do Trabalho, sob essa perspectiva thompsoniana, não entendemos os grupos envolvidos na implementação da legislação social e trabalhista no Brasil, não de forma maniqueísta vendo, apenas, dois grupos distintos e antagônicos; entre 'dominado' e 'dominador', mas ao contrário. Consideramos o operariado enquanto sujeitos históricos conscientes de sua luta e que, por isso, fazem escolhas quer concordamos com elas ou não.

Destarte, a legislação social e trabalhista não pode ser entendida simplesmente como outorga por parte das autoridades e das classes dominantes via Ministério do Trabalho, Indústria e Comércio; algo que foi imposto, mas ao contrário. A lei "não foi apenas imposta de cima sobre os homens: tem sido um meio onde outros conflitos sociais têm se travado."31

\section{CONSIDERAÇÕES FINAIS}

Ao longo deste artigo procuramos destacar a maneira a qual Lindolfo Leopoldo Boeckel Collor procurou ao longo de sua vida política a conciliação entre capital e trabalho. Para tanto, seria necessário que no Brasil houvesse uma busca para as soluções dos problemas que tangem o campo da legislação social e trabalhista genuinamente brasileira, ou seja, que estivessem de acordo com o desenvolvimento econômico do país.

Deste modo, figuras como a de Lindolfo Collor é importantes nos estudos para a compreensão de temas tão polêmicos como as leis trabalhistas no país foram incorporadas ao estado de direito pós 1930 quando este assumiu a pasta do Ministério do Trabalho, Indústria e Comércio para se evitar o que 
ocorre muitas vezes certas simplificações das mais diversas ordens, como a reduzir a Era Vargas a um corporativismo à outrance.

Ainda na Primeira República no país existiam líderes e representantes de classes que buscavam conciliar capital e trabalho. Muitos desses líderes fizeram parte junto a Lindolfo Collor do Ministério do Trabalho. Este foi um ministério em que Collor buscou dar competência técnica a ele em tivesse como causa precípua a conciliação entre classes. Esta foi a tônica de suas ações. Esta visão foi a que prevaleceu na história do Brasil quanto à legislação trabalhista que está em vigor até os nossos dias.

\section{REFERÊNCIAS}

BARROS, Orlando de. "Os intelectuais de esquerda e o ministério Lindolfo Collor". In: FERREIRA, Jorge. REIS, Daniel Aarão (Org.). A formação das tradições (1889-1945). Rio de Janeiro: Civilização Brasileira, 2007, p. 297-330.

BATALHA, Cláudio Henrique de Moraes. "A difusão do marxismo e os socialistas brasileiros na virada do século XIX". In: MORAES, João Quartim de; REIS, Daniel Aarão (Org.). História do marxismo no Brasil: os influxos teóricos. $2^{\mathrm{a}}$ ed. Campinas/SP: Editora da Unicamp, 2007. (v. 2)

CARONE, Edgard. A República Velha: instituições e classes sociais. Col. "Corpo e Alma do Brasil". 2ed. São Paulo: DIFEL, 1972.

BITTENCOURT, Dário de. Das “Ordenações Filipinas" à criação do Ministério do Trabalho: a legislação social trabalhista brasileira anterior a 1930. Porto Alegre: Tipografia Thurmann, 1938.

BRASIL. Senado Federal. Subsecretaria de Informações. Decreto no 19.433, de 26 de novembro de 1930. Cria uma Secretaria de Estado com a denominação de Ministério do Trabalho, Indústria e Comércio, disponível em: <www6.senado.gov.br/legislacao/ListaPublicacoes.action?id=\%2037466> Acessado em 10/07/2013 às 15h47.

CHAUÍ, Marilena. "Apresentação”. In: CHAUÍ, Marilena. FRANCO, Maria Sylvia Carvalho. Ideologia e mobilização popular. Rio de Janeiro: Paz e Terra/Centro de Estudos de Cultura Contemporânea (CEDEC), 1978, p. 9-16.

COLLOR, Lindolfo Leopoldo Boeckel. "A questão social”. Jornal A Tribuna, Rio de Janeiro: 15/05/1917.

$\overline{29 / 09 / 1934 .}$

"A questão social no Brasil". Correio do Povo, Rio de Janeiro,

Manifesto da Aliança Liberal. IN: BENEVIDES, Paulo e AMARAL, Roberto. 3ㅡㄹ Ed, Brasília: Senado Federal, Conselho Editorial, 2002. 
1971.

. Sinais dos tempos. Rio de Janeiro: Editora Pan Americana S/A,

. Origens da Legislação Trabalhista Brasileira. Organização e

introdução de Mário de Almeida Lima. Porto Alegre: Fundação Paulo do Couto e Silva, 1991.

FAUSTO, Boris. Trabalho Urbano e conflito social (1890-1920). 4aa ed. São Paulo: DIFEL, 1986.

GOMES, Ângela Maria de Castro (Org.). Trabalho e previdência: 60 anos em debate. Rio de Janeiro: FGV/CPDOC, 1992.

2005.

. A invenção do Trabalhismo. 3aㅡ Ed., Rio de Janeiro: Editora FGV,

HOBSBAWM, Eric J. "História operária e ideologia". In: HOBSBAWM, Eric J. Mundo do trabalho: novos estudos sobre história operária. Rio de Janeiro: Paz e Terra, 2008, p. 15-32.

MONIZ, Heitor. Heitor Muniz (depoimento, 1978). Rio de Janeiro, CPDOC, 1992. 29 p. dat

MORAES, Antônio Evaristo de. Apontamentos de direito operário. $3^{\text {a }}$ Ed, São Paulo: LTr, 1986.

MORAES FILHO, Evaristo. "A proto-história do Marxismo no Brasil". In: MORAES, João Quartim de; REIS, Daniel Aarão (Org.). História do marxismo no Brasil: o impacto das revoluções. $2^{\mathrm{a}}$ ed. Campinas/SP: Editora da Unicamp, 2007. (v. 1)

ROIO, Marcos Del. "O impacto da Revolução Russa e da Internacional Comunista no Brasil". In: MORAES, João Quartim de; REIS, Daniel Aarão (Org.). História do marxismo no Brasil: o impacto das revoluções. $2^{a}$ ed. Campinas/SP: Editora da Unicamp, 2007. (v. 1)

THOMPSON, Edward Palmer. "O domínio da Lei". In: THOMPSON, Edward Palmer. Senhores e caçadores: a origem da lei negra. Trad. Denise Bottmann. Rio de Janeiro: Paz e Terra, 1987, p. 348-361.

VÉLEZ-RODRÍGUEZ, Ricardo. "Lindolfo Collor e a plataforma modernizadora da Aliança Liberal". IN: Convívium. Revista Bimestral de Investigação e Cultura. Março/Abril, ano XXVIII, Vol. 32, no 2 de 1989.

\footnotetext{
${ }^{1}$ Doutorando em História Política pela (UNESP/Assis). É professor do curso de História da Faculdade Santa Izildinha (UNIESP/São Mateus).
} 
${ }^{2}$ HOBSBAWM, Eric J. "História operária e ideologia". In: HOBSBAWM, Eric J. Mundo do trabalho: novos estudos sobre história operária. Rio de Janeiro: Paz e Terra, 2008, p. 15.

${ }^{3}$ Idem, p. 16.

${ }^{4}$ CHAUÍ, Marilena. "Apresentação". In: CHAUÍ, Marilena. FRANCO, Maria Sylvia Carvalho. Ideologia e mobilização popular. Rio de Janeiro: Paz e Terra/Centro de Estudos de Cultura Contemporânea (CEDEC), 1978, p. 9-16.

${ }^{5}$ Sobre estas vertentes, consultar: FAUSTO, Boris. Trabalho Urbano e conflito social (18901920). $4^{\text {a }}$ ed. São Paulo: DIFEL, 1986, p. 41. BATALHA, Cláudio Henrique de Moraes. "A difusão do marxismo e os socialistas brasileiros na virada do século XIX". In: MORAES, João Quartim de; REIS, Daniel Aarão (Org.). História do marxismo no Brasil: os influxos teóricos. 2 ${ }^{\mathrm{a}}$ ed. Campinas/SP: Editora da Unicamp, 2007. (v. 2) p. 9. MORAES FILHO, Evaristo. "A protohistória do Marxismo no Brasil". In: MORAES, João Quartim de; REIS, Daniel Aarão (Org.). História do marxismo no Brasil: o impacto das revoluções. $2^{a}$ ed. Campinas/SP: Editora da Unicamp, 2007. (v. 1) p. 36 e segs.

${ }^{6}$ BATALHA, Cláudio Henrique de Moraes. Op. Cite. p. 9 e segs.

${ }^{7}$ FAUSTO, Boris. Op. Cite. p. 97.

${ }^{8}$ ROIO, Marcos Del. "O impacto da Revolução Russa e da Internacional Comunista no Brasil". In: MORAES, João Quartim de; REIS, Daniel Aarão (Org.). História do marxismo no Brasil: o impacto das revoluções. 2ª ed. Campinas/SP: Editora da Unicamp, 2007. (v. 1), p. 59.

${ }^{9}$ GOMES, Ângela Maria de Castro. A invenção do Trabalhismo. $3^{\text {a }}$ Ed., Rio de Janeiro: Editora FGV, 2005, p. 81.

${ }^{10}$ Como é sabido de todos, a proposta anarquista recusava a definição da práxis política enquanto disputa eleitoral ou qualquer prática partidária. Contudo, assim como GOMES, Ângela Maria de Castro. Idem. p. 83, entendemos que essa ação não se limitava a uma negligência da dimensão da política, mas ao contrário, como outra opção de se lidar com ela e, ao mesmo tempo, que se redefinia sua ação política.

${ }^{11}$ CARONE, Edgard. A República Velha: instituições e classes sociais. Col. "Corpo e Alma do Brasil". 2ed. São Paulo: DIFEL, 1972. p. 243.

12 Embora nesse artigo citamos apenas três correntes contestatória que influenciaram o movimento operário brasileiro, não ignoramos a existência de outras vertentes as quais também existiram aqui bem como a influência das Revoluções socialistas ao redor do mundo: a Revolução Russa, o Leninismo de Stálin, o Maoísmo.

${ }^{13}$ FAUSTO, Boris. Op. Cite. p. 41.

14 COLLOR, Lindolfo Leopoldo Boeckel. Sinais dos tempos. Rio de Janeiro: Editora Pan Americana S/A, 1971. p. 7.

${ }^{15}$ Idem, p. 5.

${ }^{16}$ MONIZ, Heitor. Heitor Muniz (depoimento, 1978). Rio de Janeiro, CPDOC, 1992. 29 p. dat.

${ }^{17}$ VÉLEZ-RODRÍGUEZ, Ricardo. "Lindolfo Collor e a plataforma modernizadora da Aliança Liberal". IN: Convívium. Revista Bimestral de Investigação e Cultura. Março/Abril, ano XXVIII, Vol. 32, no 2 de 1989. p. 102. Neste artigo o autor discute a influência do castilhismo na vida de Lindolfo Collor e afirma que os ideais castilhistas que o nortearam foram: o conceito de bem público, a ideia de democracia representativa, a concepção de justiça social e a sua visão de política econômica. 
${ }^{18}$ COLLOR, Lindolfo Leopoldo Boeckel. "A questão social". Jornal A Tribuna, Rio de Janeiro: 15/05/1917. (Grifos nosso).

${ }^{19}$ Idem, Ibidem.

${ }^{20}$ COLLOR, Lindolfo Leopoldo Boeckel. "A questão social no Brasil". Correio do Povo, Rio de Janeiro, 29/09/1934. (Grifos Nossos)

${ }^{21}$ BITTENCOURT, Dário de. Das "Ordenações Filipinas" à criação do Ministério do Trabalho: a legislação social trabalhista brasileira anterior a 1930. Porto Alegre: Tipografia Thurmann, 1938. p. 27

${ }^{22}$ Idem, Ibidem.

${ }^{23}$ GOMES, Ângela Maria de Castro (Org.). Trabalho e previdência: 60 anos em debate. Rio de Janeiro: FGV/CPDOC, 1992. p. 8

${ }^{24}$ Apud. COLLOR, Lindolfo Leopoldo Boeckel. Manifesto da Aliança Liberal. IN: BENEVIDES, Paulo e AMARAL, Roberto. 3aㅡ Ed, Brasília: Senado Federal, Conselho Editorial, 2002. p. 154155.

${ }^{25}$ Cf. Brasil. Senado Federal. Subsecretaria de Informações. Decreto $n^{\circ}$ 19.433, de 26 de novembro de 1930. Cria uma Secretaria de Estado com a denominação de Ministério do Trabalho, Indústria e Comércio, disponível em: $<w w w 6$.senado.gov.br/legislacao/ListaPublicacoes.action?id=\%2037466> Acessado em $10 / 07 / 2013$ às $15 \mathrm{~h} 47$.

${ }^{26}$ BARROS, Orlando de. "Os intelectuais de esquerda e o ministério Lindolfo Collor". In: FERREIRA, Jorge. REIS, Daniel Aarão (Org.). A formação das tradições (1889-1945). Rio de Janeiro: Civilização Brasileira, 2007, p. 305.

${ }^{27}$ Idem, p. 305.

${ }^{28}$ Discurso de Lindolfo Collor, por ocasião da posse no Ministério do Trabalho, em cerimônia realizada no Salão do Ministério da Justiça, em 1ำ de dezembro de 1930. Cf. COLLOR, Lindolfo Leopoldo Boeckel. Origens da Legislação Trabalhista Brasileira. Organização e introdução de Mário de Almeida Lima. Porto Alegre: Fundação Paulo do Couto e Silva, 1991. p. 180.

${ }^{29}$ Discurso de Lindolfo Collor, pronunciado no Rotary Club, em 26 de dezembro de 1930.

IN:COLLO.R, Idem. p. 186/187. (Grifos Nosso).

30 THOMPSON, Edward Palmer. Senhores e caçadores: a origem da lei negra. Trad. Denise Bottmann. Rio de Janeiro: Paz e Terra, 1987, p. 354. (Grifo nosso).

${ }^{31}$ Idem, p. 358.

RECEBIDO EM: dezembro/2013

APROVADO EM: dezembro/2013 